\title{
The Destruction and Transformation \\ of the Crystal Lattice of Alumina \\ by Mechanical Activation
}

\author{
Olga V. Yushkova (Belonogova)*a, \\ Valentina I. Aniquina a and Sergey M. Zharkov ${ }^{\mathrm{b}}$ \\ ${ }^{a}$ Siberian Federal University \\ 79 Svobodniy, Krasnoyarsk, 660041, Russia \\ ${ }^{b}$ Kirensky Institute of Physics $S B R A S$ \\ 50 Akademgorodok, Krasnoyarsk, 660036, Russia
}

Received 29.12.2014, received in revised form 24.06.2015, accepted 19.09.2015

We studied the influence of mechanical activation (MA) of alumina to modify its crystal lattice and on the dissolution rate in molten fluorides during electrolysis. The changes in phase compositioneducation x-ray amorphous alumina after MA mills: planetary and vibratory. Studied structural changes in mechanically activated oxide phases such as alumina example, $\alpha-\mathrm{Al}_{2} \mathrm{O}_{3}$. The images confirmed that the dominant slip plane in the structure of corundum is the basal plane $\{111\}$.

Keywords: alumina, mechanical activation.

DOI: $10.17516 / 1999-494 X-2015-8-7-851-860$.

\section{Разрушение и трансформация \\ кристаллической решетки глинозема \\ при механоактивации}

О.В. Юшкова (Белоногова) ${ }^{\mathrm{a}}$, В.И. Аникина ${ }^{a}$, С.М. Жарков ${ }^{\tilde{0}}$

${ }^{a}$ Сибирский федеральный университет Россия, 660041, Красноярск, пр. Свободный, 79 ${ }^{6}$ Институт физики имени Л.В. Киренского СО РАН Россия, 660036, Красноярск, Академгородок, 50

Изучено влияние механоактивачии (МА) глинозема на изменение параметров его кристаллической решетки и на скорость растворения в расплаве фторидов при электролизе.

(c) Siberian Federal University. All rights reserved

* Corresponding author E-mail address: olga_yushkova_1954@mail.ru 
Установлено изменение фазового состава - образование рентгеноаморфного глинозема после МА в планетарной и вибрационной мельницах. Изучены структурные изменения в механоактивированных оксидных фазах типа корунда на примере $\alpha-\mathrm{Al}_{2} \mathrm{O}_{3}$. Снимками подтверждено, что преобладающей плоскостью скольжения в структуре корунда является базисная плоскость $\{111\}$.

Ключевые слова: глинозем, механоактивачия.

Памяти Кулебакина Виктора Григорьевича, доктора технических наук, посвящается

\section{Введение}

Электролитический способ остается основным при производстве алюминия. Этот способ основан на электрохимическом разложении глинозема, растворенного в криолитовом расплаве [1], процесс которого может зависеть от свойств глинозема, температуры и режимов электролиза [2]. Улучшить свойства глинозема можно путем механоактивации [3].

Для электролитического получения алюминия применяется глинозем в виде корунда $\alpha \mathrm{Al}_{2} \mathrm{O}_{3}$. В решетке корунда каждый ион алюминия связан с шестью ионами кислорода, находящимися практически на равных расстояниях от него. Следовательно, эту структуру можно рассматривать как плотную гексагональную упаковку ионов кислорода, октаэдрические поры которой заняты ионами алюминия (рис. 1) [4].
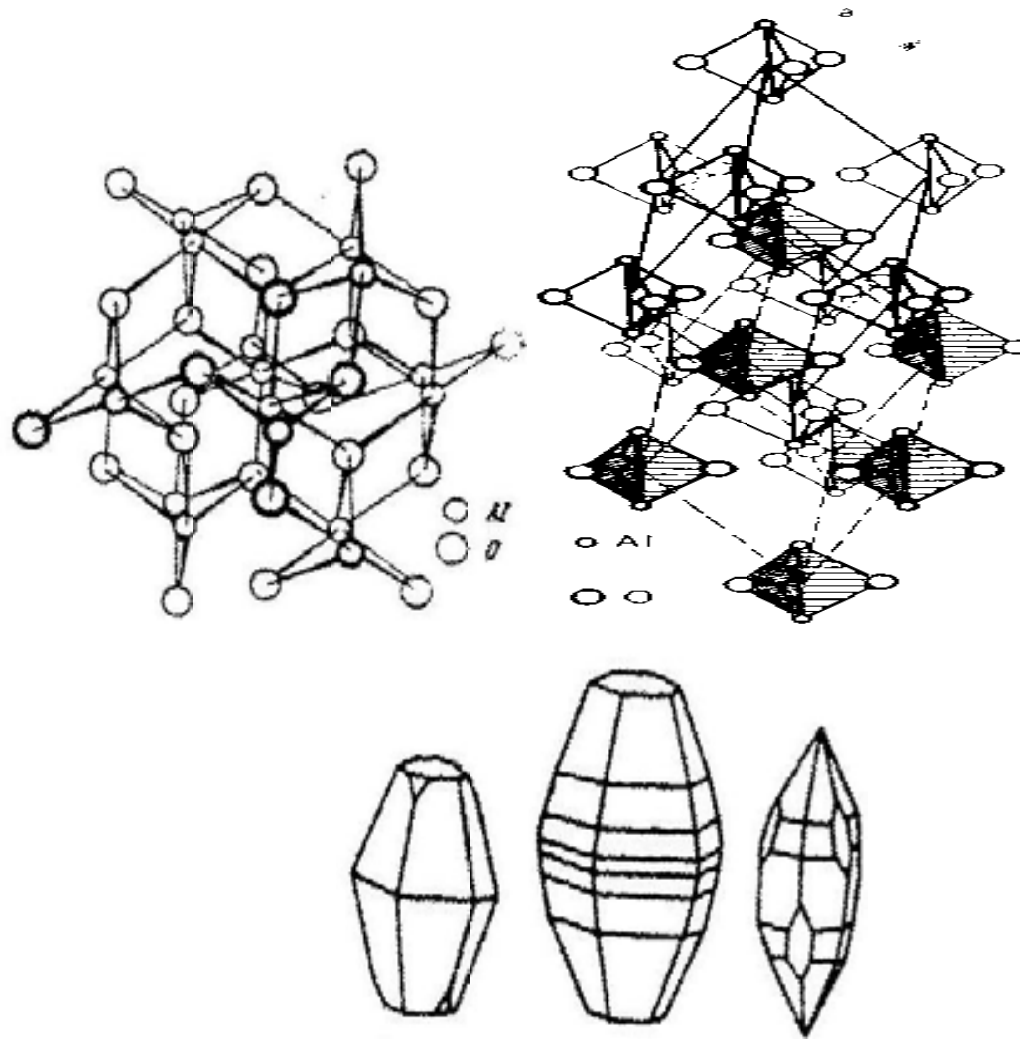

Рис. 1. Элементарная ячейка корунда (по Ормонту) 
Данная работа посвящена изучению влияния процесса механической активации (МА) на скорость растворения глинозема. Этот способ достаточно изучен и описан [1], однако механизм влияния механоактивации на изменение кристаллической решетки глинозема авторы рассматривают по-разному.

Объектом данного исследования является глинозем Николаевского глиноземного комбината марки Г- 00 к.

Исследовали влияние различных режимов механической активации (МА) на физикомеханические свойства глинозема (гранулометрический состав, удельную поверхность $\left(\mathrm{S}_{\text {уд.). }}\right)$.

Для МА глинозёма применяли мельницы периодического действия: планетарную М-3 конструкции Голосова (рис. 2a) (в дальнейшем М-3) с различным соотношением массы загрузки порошков и массы мелющих тел, продолжительности активации и работы $[5,6]$.

M-3 - высокоэнергонапряженный аппарат с двумя металлическими барабанами, вращающимися вокруг осей: собственной и отнесенной на некоторое расстояние. Вращение каждого барабана имеет направление, противоположное вращению системы из двух барабанов, жестко связанных водило́м, обеспечивающим «планетарное» движение барабанов с пробой (рис. 2a). В барабан загружается заданный объем мелющих тел (в нашем случае железные шары диаметром 3 мм) и навески глинозема массой 10 г. Мелющие тела занимают 60 \% объема рабочей камеры. Активируемый материал находится под действием значительных центробежных сил (50 g в M-3)), что позволяет получать продукты большой дисперсности за сравнительно небольшое время. Каждый из барабанов М-3 с внутренним объемом 600 см$^{3}$ вращается со скоростью 1000 об/мин. Количество оборотов системы из двух барабанов равно 425 об/мин. Мощность электродвигателя М-3 составляет 2,8 кВт. После МА глинозем выгружается из барабана, отделяется от мелющих тел.

CВУ-2 - вибрационный аппарат, в рабочей камере которого производится обработка материала стальными стержнями, перемещающимися в различных направлениях за счет вибрации корпуса в вертикальной плоскости. Корпус приводится в движение вибровозбудителем (рис. 2б), обеспечивающим заданную частоту вибраций (от 25 до 50 Гц и более) и амплитуду не более 2-3 мм. Стержни занимают до 80-90 \% объема рабочей камеры [7].

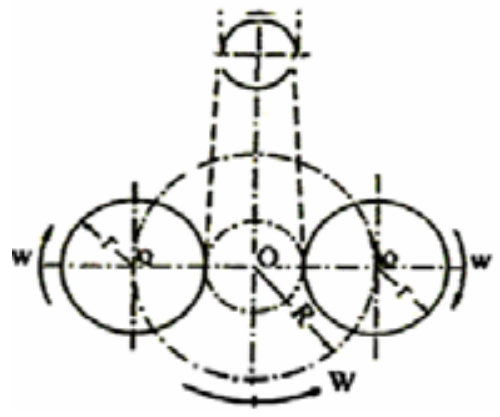

a
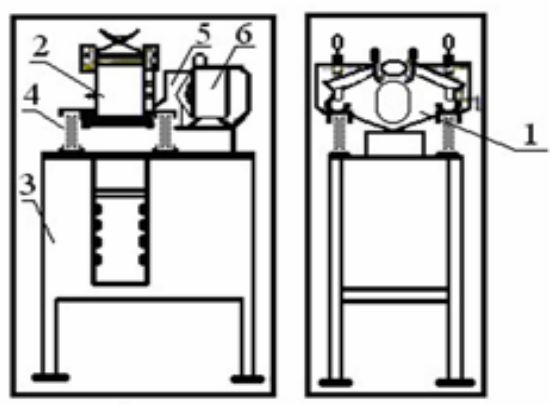

6

Рис. 2. Принципиальная схема работы: a - планетарной мельницы - M-3: R и r - радиусы водила и барабана; W и w - угловые скорости вращения водила и барабана; O и о - центры вращения водила и барабана; б - вибрационной мельницы СВУ-2: 1 - вибровозбудитель; 2 - камера контейнера; 3 - стол; 4 - опорная пружина; 5 - упругая муфта; 6 - электродвигатель 
Промышленный аппарат СВУ-2 (10-15 g) по сравнению с шаровыми мельницами вращательного типа обеспечивает интенсификацию процесса в 5-10 раз, позволяя осуществить сухое и мокрое измельчение в вакууме или в контролируемой газовой среде. СВУ-2 представляет интерес как аппарат, производительность промышленных вариантов которого достигает 10 т/ч и более. Вещество загружается вместе с мелющими телами в камеру контейнера.

Анализ механически обработанных порошков $\mathrm{Al}_{2} \mathrm{O}_{3}$ в высокоэнергонапряженных активаторах планетарного типа показал значительное изменение свойств глинозема [3].

Наибольшей реакционной способностью обладают атомы или ионы, расположенные на вершинах кристалла, затем на ребрах и далее атомы или ионы, расположенные на гранях. Таким образом, при измельчении кристаллов активность твердого вещества повышается не только за счет увеличения доли поверхностных атомов, но и вследствие увеличения числа атомов, расположенных на самых активных местах кристалла (вершинах и ребрах) по сравнению с числом атомов, находящихся на гранях.

Высокую скорость растворения механоактивированного глинозема и его реакционную способность с повышением дисперсности авторы [8] объясняют тем, что частицы твердого вещества, расположенные на поверхности или близ нее, обладают большей свободной энергией, чем частицы во внутренних частях кристаллов [8].

Авторы работы [9] показывают, что при механическом воздействии шара на слой порошка плотность увеличивается. Одновременно с этим меняется и механизм пластической деформации - от хрупкого разрушения и скольжения частиц друг по другу при сыпучем состоянии среды к деформации уплотненной среды как твердого тела к истинной дислокационной пластичности. В первом случае дефекты кристаллической решетки образуются в приповерхностных областях частиц, во втором - во всем объеме частиц. Переход к объемной деформации частиц совершается тогда, когда напряжения трения, действующие на контактах частиц друг с другом и с шарами, сравниваются с критическим напряжением сдвига материала.

Переходные формы, образующиеся при обработке гидроксида алюминия по [10], представлены на рис. 3. При механоактивации изменение дисперсности глинозема и переход от кристаллической структуры к рентгеноаморфной позволяют потенциалу возрасти на несколько тысяч калорий на моль, приводящих к изменению константы равновесия в десятки и даже сотни тысяч раз, что может отразиться на скорости реакции.

Процессы растворения, флотации, трехфазного синтеза сложных соединений протекают таким образом, что состояние поверхности их поликристаллов имеет определяющее значение.

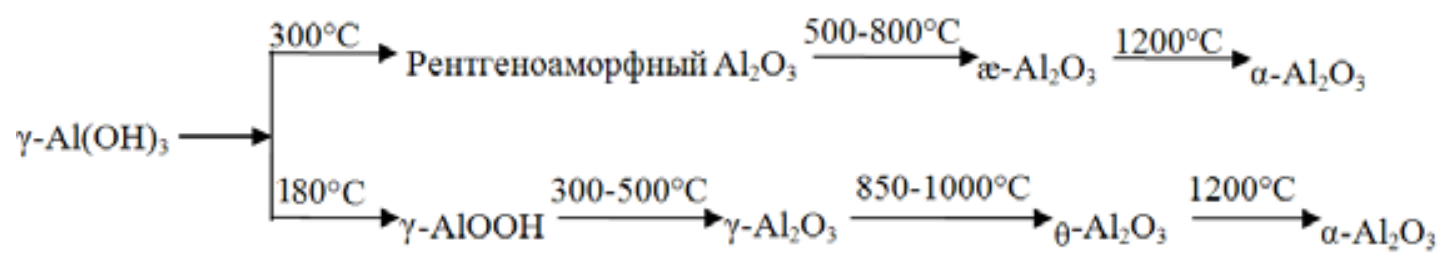

Рис. 3. Обобщенная схема фазовых превращений гидроксида алюминия по [10] в зависимости от режимов обработки. 
Изучая последовательность процессов, происходящих при МА оксидов, авторы [11] установили, что при ударе мелющего тела в результате раскола частиц материала наблюдается появление бо́льшего количества кристалллографических плоскостей $\{020\}\{040\},\{060\}$ по сравнению с $\{021\}$ и другими. Разрушение кристаллов сопровождается увеличением удельной поверхности и агрегированием активируемых частиц. Известно, что в момент удара при столкновении твердых тел в точках их соприкосновения температура может достигать $1300 \mathrm{~K}$. В [11] сообщают, что во время удара частицы разогреваются до температуры, составляющей $2 / 3$ от температуры плавления. Это приводит к слипанию частиц в более крупные блоки с образованием агрегатов из тонкодисперсного материала, а связей «металл-кислород» - к разрыву [11].

Следствием механохимического воздействия на твердое тело является образование дислокаций [12]). Дефектную структуру активированного материала определяет движение дислокаций и их взаимодействие. Удары мелющих тел облегчают передвижение дислокаций в глиноземе, что способствует переходу материала в другое состояние. Если есть другие дефекты, то дислокации нагромождаются и увеличивают напряжение в решетке, что приводит к растрескиванию и повышению реакционной способности.

Структура $\gamma-\mathrm{Al}_{2} \mathrm{O}_{3}$ относится к структуре шпинели дефектного типа с недостатком ионов металла. Модификация $\gamma-\mathrm{Al}_{2} \mathrm{O}_{3}$ (рис. 4) характеризуется большой гигроскопичностью. Альфа $\mathrm{Al}_{2} \mathrm{O}_{3}$, как наиболее стабильная, растворяется медленнее, чем менее устойчивая $\gamma-\mathrm{Al}_{2} \mathrm{O}_{3}$ и переходные формы $\theta-\mathrm{Al}_{2} \mathrm{O}_{3}, \delta-\mathrm{Al}_{2} \mathrm{O}_{3}$ и др. [13].

Авторы [14] исследовали структурные изменения в механоактивированных оксидных фазах типа корунда на примере $\alpha-\mathrm{Al}_{2} \mathrm{O}_{3}$ и утверждают, что преобладающей плоскостью скольжения в структуре корунда является базисная плоскость (0001). Скольжение дислокаций происходит при совместном смещении катионных и анионных сеток с сохранением октаэдрической координации катионов. Последовательность чередования слоев изменяется по причине расщепления дислокаций. Это соответствует образованию протяженных (плоских) дефектов упаковки (ДУ). Катионные ДУ образуются при прохождении половинных дислокаций, а при прохождении четвертичных возникают катионные и анионные ДУ. Двойниковые ДУ появляются путем последовательных послойных смещений анионных слоев за счет четвертичных дисло-
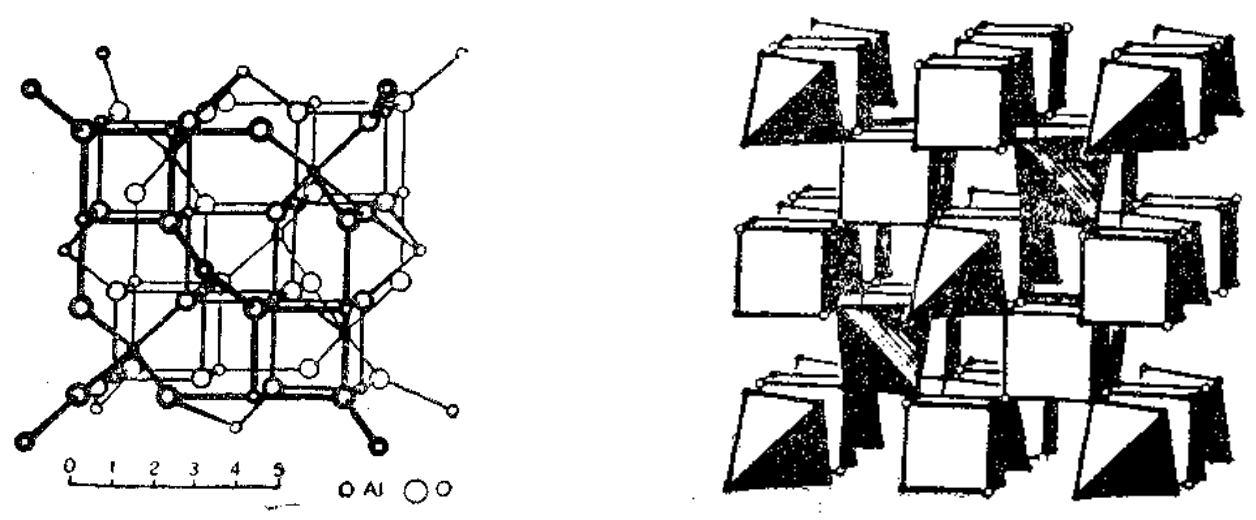

Рис. 4. Модель структуры $\gamma-\mathrm{Al}_{2} \mathrm{O}_{3}$ (по Ормонту) 
каций с соответствующими синхросдвигами промежуточных катионов. Образование остаточных микроискажений в решетке и указанные дефекты упаковки приводят к изменению реакционной способности данных оксидов, что способствует ускорению процессов растворения. На рис. 4 приведена модель $\gamma-\mathrm{Al}_{2} \mathrm{O}_{3}$, структура и местоположение ионов $\mathrm{Al}^{3+}$ и $\mathrm{O}^{2-}$.

Известно [9-12], что при МА твердых тел происходит накопление различных типов дефектов, что ведет к увеличению реакционной способности. Первоначально при МА твердых частиц происходит их измельчение, т.е. увеличение площади поверхности.

Физико-механические свойства глинозема до и после МА определяли различными методами.

\section{Материалы и методы}

В данной работе измерение физико-механических свойств глинозема осуществляли согласно стандартным методикам:

- Рентгенофазовый анализ (РФА) проводили с использованием рентгеновского дифрактометра марки «ДРОН-3» на медном $(\mathrm{Cu} \mathrm{K \alpha})$ излучении со скоростью движения диаграммной ленты 800 мм/ч (2 градуса в минуту). Напряжение на рентгеновской трубке составляло 31 кВ, сила тока - 31 мА. Межплоскостные расстояния $(d)$ рассчитывали по таблицам Гиллера, а расшифровку рентгенограмм (дифрактограмм) выполняли с использованием эталонов американской картотеки ASTM.

- Снимки исходных и активированных фракций нефторированного и фторированного (после газоочистки) глиноземов выполняли на растровом электронном микроскопе «РЭМ-100».

- Удельную поверхность $\left(\mathrm{S}_{\text {уд. }}\right)$ замеряли методом низкотемпературной адсорбции газообразного азота на поверхности вещества на «Ареаметре-11».

- Гранулометрический состав глиноземов двух параллельных определений измеряли на анализаторе частиц «Микросайзер» модели $201 \mathrm{C}$ и ситовым методом (неактивированный продукт). Глинозем после МА ситовым методом измерить невозможно из-за агрегирования.

- Исследования микроструктуры проведены на просвечивающем электронном микроскопе JEOL JEM-2100 (при ускоряющем напряжении 200 кВ). Пробоподготовка - порошок поместили в этиловый спирт, диспергировали в течение 2 мин в ультразвуковой ванне, потом взвесь нанесли на углеродную пленку-подложку, находящуюся на электронномикроскопической поддерживающей сеточке.

Электронно-микроскопические исследования проведены в Центре коллективного пользования Сибирского федерального университета.

\section{Результаты}

Результаты РФА представлены на рис. 5.

По результатам РФА исходной пробы нефторированный глинозем состоит из модификаций $\mathrm{Al}_{2} \mathrm{O}_{3}$ : а) тетрагональной $\left(\delta-\mathrm{Al}_{2} \mathrm{O}_{3}-\mathrm{ASTM}, 46-1131\right)$, преобладающей с межплоскостными расстояниями $(d)$ интенсивных широких рефлексов на дифрактограмме, равными 0,1390 ; 0,$1401 ; 0,1988 ; 0,1952 ; 0,238 ; 0,228$ нм, и более слабого рефлекса на дифрактограмме с $d=0,1533$

$$
-856-
$$


нм; б) кубической $\left(\gamma-\mathrm{Al}_{2} \mathrm{O}_{3}-\mathrm{ASTM}, 29-63\right) \mathrm{c} d=0,1401 ; 0,1988 ; 0,238 ; 0,228$ нм (ее рефлексы совпадают с таковыми $\left.\delta-\mathrm{Al}_{2} \mathrm{O}_{3}\right)$; в) ромбоэдрической $\left(\alpha-\mathrm{Al}_{2} \mathrm{O}_{3}-\mathrm{ASTM}, 46-1212\right)$ с $d=0,254$; 0,$209 ; 0,1598 ; 0,1732$ и 0,345 нм.

После МА в М-3 интенсивность большинства рефлексов на дифрактограмме, особенно самого сильного с $d=0,1390$ нм, стала меньше (рис. 5, кривые 1 и 3). Граница наложения кубической модификации на тетрагональную сгладилась. На рентгенограмме в пробах глинозема, активированного в СВУ-2 в течение 5 мин, зафиксированы некоторые изменения фазового состава.

Наряду с уже идентифицированными фазами $\mathrm{Al}_{2} \mathrm{O}_{3}$ появились рефлексы новой (ASTM, 34-0493 - $\chi$ ). После 15 мин МА в СВУ-2 также отмечаются некоторые структурные изменения, очевидные из раздвоения линии с $d=0,238$ нм. Появилась новая линия с $d=0,240$ нм. Глинозем, кристаллизующийся в кубической сингонии, разрушается, переходя в ромбоэдрическую $\alpha-\mathrm{Al}_{2} \mathrm{O}_{3}$ (ASTM 46-1212) с $d=0,255$ и 0,1601 нм. Рефлексы стали менее широкими, наложение разных фаз более выраженным, а интенсивность несколько бо́льшей, чем после МА в М-3. По [8] при обработке гидроксида алюминия могут образоваться как высокоупорядоченные $(\chi$-, $\kappa$-, $\left.\alpha-\mathrm{Al}_{2} \mathrm{O}_{3}\right)$, так и менее упорядоченные $\left(\gamma-, \delta-\mathrm{Al}_{2} \mathrm{O}_{3}\right)$ фазы глинозема (рис. 3). Скорость растворения глинозема в электролите зависит от степени упорядоченности вещества в решетке. Появление высокоупорядоченной фазы $\chi-\mathrm{Al}_{2} \mathrm{O}_{3}$ после МА глинозема подтверждает, что переход $\gamma-$ $\mathrm{Al}_{2} \mathrm{O}_{3}$ в $\alpha-\mathrm{Al}_{2} \mathrm{O}_{3}$ через фазу $\chi-\mathrm{Al}_{2} \mathrm{O}_{3}$ по кратчайшей схеме перехода (рис. 3,4 ) как при медленном нагреве. $\left.\mathrm{Al}_{2} \mathrm{O}_{3}\right) \mathrm{c} d=0,139$ и 0,240 нм (рис. 5).

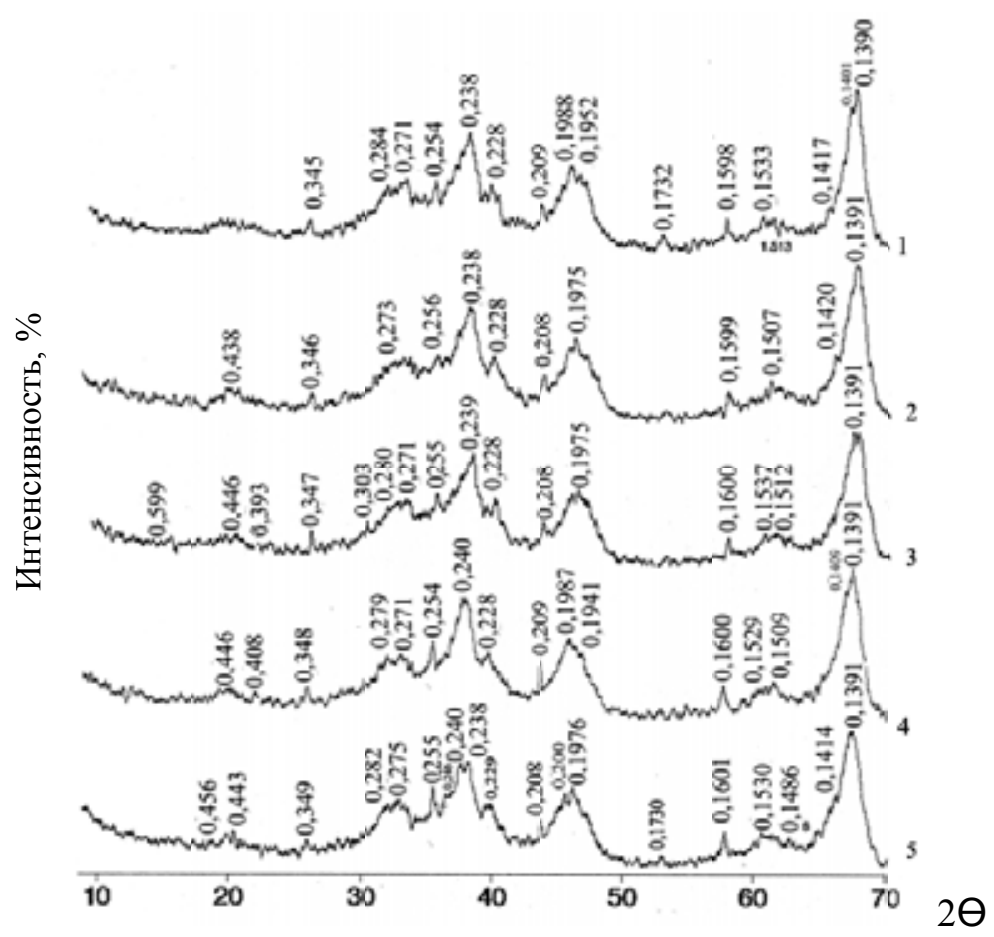

Рис. 5. Дифрактограммы нефторированного глинозема: 1 - (исходного); 2-5 - активированного в мельницах: 2-3 - М-3 - 30 с и 5 мин; 4-5 - СВУ-2 - 5 и 15 мин 
Увеличение свободной поверхности и аккумуляция энергии в поверхностном слое и в зонах остаточного напряжения приводит к механохимическим превращениям, таким как: а) химические реакции при измельчении, б) физико-химические превращения при измельчении, например: 1) переход в другую модификацию; 2) аморфизация кристаллических веществ; 3) изменение координационного числа иона $\mathrm{Al}$ в кристаллической решетке, что подтверждается авторами [15]. Результаты электронно-микроскопических исследований глинозема (рис. 6a) показали, что в исходном состоянии его частицы представляют кристаллы. Их формы - прямоугольные, ромбические и гексагональные пластины и призмы - характерны для корунда и других переходных фаз [3]. Если в исходной фракции они одинаковые по размерам и достаточно огранены, то в активированной имеют значительный разброс по крупности и сбитые вершины и трещины по ребрам (рис. 6б).

Даже при большом увеличении видно, что после МА мелкие частички приближены к крупным частицам и собраны в агрегаты.

Электронно-микроскопические исследования (рис. 7) показали, что в образце содержится: 1) крупная фракция - размер частиц 1-10 мкм, возможно и больше, но из-за особенностей пробоподготовки более крупная фракция могла не попасть на электронно-микроскопическую сеточку; 2) мелкая фракция - частицы со средним размером (11 5 нм).

Особенностью данного процесса является то, что частицы на пленке-подложке когерентно подстраиваются друг к другу, вследствие этого на электронограммах наблюдаются точечные рефлексы, характерные для монокристаллических структур.

\section{Обсуждение результатов}

Исследования закономерностей МА и дефектов, образующихся в оксидах, подтверждают, что изменения стехиометрии может происходить за счет образования сдвиговых структур при перегруппировке октаэдров, в центре которых находится металл, а в вершинах - ионы кислорода. В оксидах октаэдры соединены вершинами, а в дефектных структурах соседние

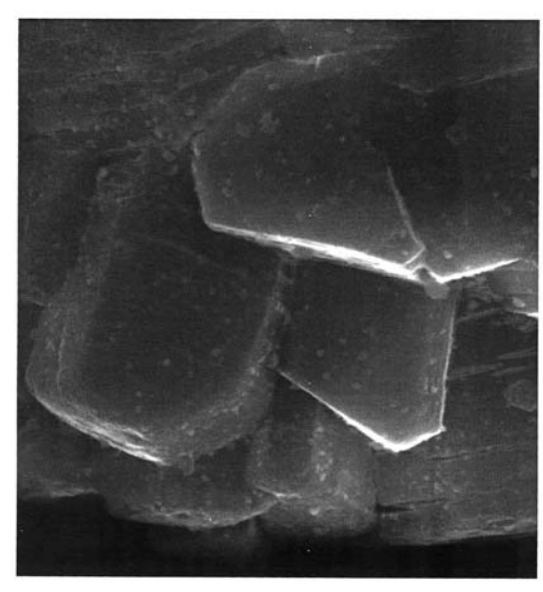

a

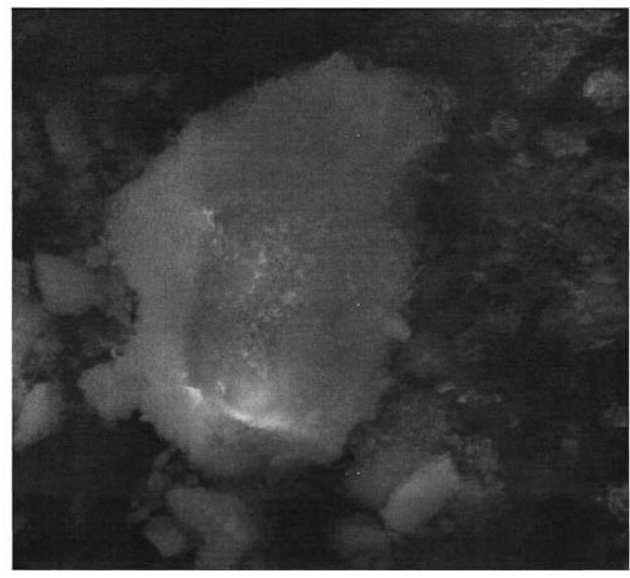

б

Рис. 6. Микрофотографии глинозема: исходного: $\mathrm{a}-\times 3000$; и $6-\times 3000$ активированного в М-3 в сухом режиме в воздушной среде в течение $10 \mathrm{c}$ 


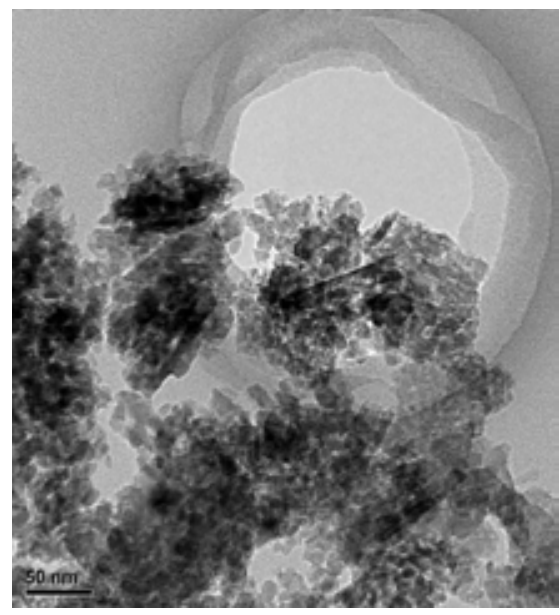

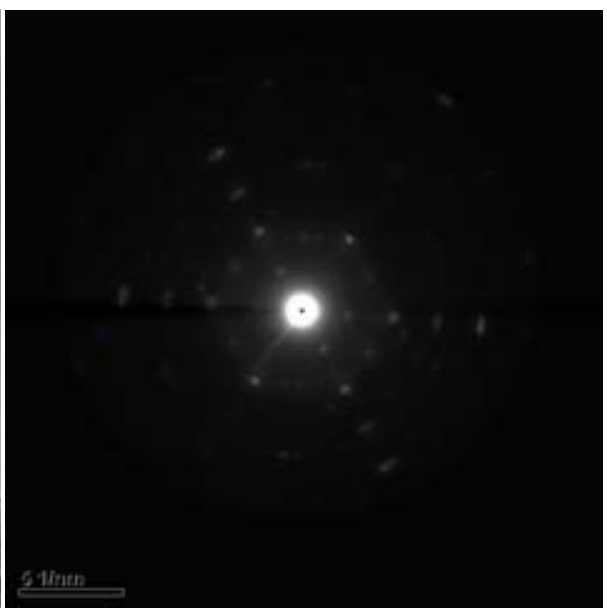

6

Рис. 7. Корунд: а - микроструктура корунда, полученная на просвечивающем электронном микроскопе, $\times 50000,6$ - электронограмма плоскости корунда (111)

октаэдры могут контактировать и ребрами или гранями. МА твердых тел сопровождается локальными разогревами на поверхностях разрушения и интенсивной пластической деформацией, результатом которой является генерирование и движение дислокаций. На поверхностях скола и в ядрах дислокаций возможно концентрирование энергии, достаточной для отрыва иона кислорода от оксида, т.е. их частичной механохимической диссоциации. Степень реализации эффектов МА зависит от интенсивности подводимой механической энергии. Отсутствие экзоэффекта на ДТА связано с окислением частично востановившегося при МА оксида. МА облегчает диссоциацию молекул $\mathrm{Al}_{2} \mathrm{O}_{3}$. Частицы активированного глинозема являются центрами ускоренного растворения в результате улучшения смачиваемости и уменьшения температуры фазового перехода $\left(\gamma-\mathrm{Al}_{2} \mathrm{O}_{3}-\right.$ рентгеноаморфный глинозем $\left.-\alpha-\mathrm{Al}_{2} \mathrm{O}_{3}\right)$ после МА в планетарной мельнице М-3 (50 g) или $\left(\gamma-\mathrm{Al}_{2} \mathrm{O}_{3}-\chi-\mathrm{Al}_{2} \mathrm{O}_{3}-\alpha-\mathrm{Al}_{2} \mathrm{O}_{3}\right)$ после МА в вибрационной мельнице СВУ-2 (15 g).

Идентификация картины дифракции электронов, полученной методом микродифракции от группы частиц, показала, что рефлексы соответствуют фазе sigma- $\mathrm{Al}_{2} \mathrm{O}_{3}$ (Fd3m) - PDF card \# 00-047-1292 с осью зоны \{111\}. Уплотнение материала при МА происходит сначала за счет измельчения частиц и более полного заполнения пор образующимися осколками, потом за счет агрегирования частиц в монолит.

\section{Заключение}

1. Напряжения при механической активации способствуют разрушению кристаллической решетки глинозема сколом и последующему смещению атомных плоскостей, приводящих к реконструированию кристаллической решетки кубической - ГЦК $\left(\gamma-\mathrm{Al}_{2} \mathrm{O}_{3}\right)$ в ромбоэдрическую - $\left(\alpha-\mathrm{Al}_{2} \mathrm{O}_{3}\right)$.

2. Полученные результаты свидетельствуют о том, что скол произошел по наиболее плотноупакованным плоскостям $\{111\}$.

$$
-859-
$$




\section{Список литературы}

[1] Беляев А.И., Рапопорт М.Б., Фирсанова Л.А. Электрометаллургия алюминия. М.: Металлургиздат, 1953. $712 \mathrm{c.}$

[2] Исаева Л.А., Глинозем в производстве алюминия электролизом. Краснотурьинск: БАЗ, 2000. $199 \mathrm{c}$.

[3] Юшкова О.В., Кулебакин В.Г., Поляков П.В. // Известия ВУЗов. Химия и химическая технология. 2007. Т. 50. Вып. 12. С. 123-124.

[4] Шаскольская М.П. Кристаллография: учеб. пособие. М.: Высш. шк., 1984. 376 с.

[5] Голосов С.И. // Механохимические явления при сверхтонком измельчении: сб. научных трудов ИГиГ СО АН СССР. Новосибирск, 1971. С. 23-40.

[6] Голосов С.И., Молчанов В.И. // Физико-химические изменения минералов в процессе сверхтонкого измельчения: сб. научн. трудов ИГиГ СО АН СССР. Новосибирск, 1966. С. 525.

[7] Ковшик А.В. // Наука производству: развитие прикладных исследований и внедрение их в производство в современных условиях: материалы 2-й национальной конференции. АлмаАты, 2003. С. 132-138.

[8] Кириченко О.А., Ушаков В.А., Андрюшкова О.А. и др. // Неорганические материалы. 1999. Т. 35. № 3. С. 333-341.

[9] Неверов В.В., Чернов А.А., Житников П.П. и др. // Изв. СО АН СССР. Сер. Хим. науки.1986. Вып. 5. № 15. С. 35-40.

[10] Толчеев А.В., Клешев Д.Г., Лопушан В.И. // ЖПХ. 2002. Т. 75. Вып. 2. С. 1417-1421.

[11] Полубояров В.А., Андрюшкова О.В., Болдырев В.В. и др. // Физико-технические проблемы разработки полезных ископаемых. 1993. № 1. С. 98-107.

[12] Гольдберг Е.Л., Павлов С.В. // Сибирский химический журнал. 1992. Вып. 4. С. 147150.

[13] Ханамирова A.A. Глинозем и пути уменьшения содержания в нем примесей. Ереван: Изд-во АН Армянской ССР, 1983. 243 с.

[14] Аввакумов Е.Г. Механические методы активации химических процессов. Новосибирск: Наука, 1986. 297 с.

[15] Молчанов В.И., Селезнева О.Г. // ФТПРПИ. 1979. № 6. С. 60-75. 